\title{
Fontes de proteína e carboidratos para cães e gatos
}

\section{Aulus Cavalieri Carciofi}

Departamento de Clínica e Cirurgia Veterinária, Faculdade de Ciências Agrárias e Veterinárias, Universidade Estadual Paulista - UNESP, campus de Jaboticabal. Via de Acesso Prof. Paulo Donato Castellane, s/n. Jaboticabal - SP. CEP: 14.884-900. Tel.: (16) 3209-2631. Fax: (16) 3203-1226

RESUMO: O mercado de alimentos para cães e gatos absorve importante quantidade de proteínas e carboidratos, apesar disso poucos estudos existem sobre digestibilidade e energia metabolizável destes ingredientes. Arroz e milho têm sido considerados as melhores fontes de amido, mas demonstra-se que o sorgo é igualmente bem digerido por cães. Na interpretação dos estudos, deve-se distinguir os que empregaram farinhas ou amidos purificados dos que empregaram ingredientes moídos, como utilizado na fabricação de alimentos para animais de companhia. Além de sua digestibilidade e valor energético, amidos interferem na glicemia de cães, o que torna interessante se empregar, para animais em condições específicas, fontes de carboidrato que levem à menores respostas de glicose e insulina. Devido a elevada necessidade de proteína, ingredientes protéicos são importantes nas formulações. Proteínas de origem animal apresentam maior variação em composição química, qualidade e digestibilidade que as de origem vegetal. Farinhas de origem animal podem apresentar excesso de matéria mineral, limitando sua inclusão na fórmula, enquanto derivados protéicos vegetais apresentam diversos fatores anti-nutricionais que devem ser inativados durante seu processamento. Demonstra-se que proteínas vegetais apresentam boa digestibilidade e energia metabolizável para cães e gatos, sendo sua inclusão interessante para reduzir a matéria mineral da dieta, controlar o excesso de bases do alimento e manter adequada a digestibilidade do produto, neste sentido soja micronizada e o farelo de glúten de milho $60 \%$ se destacam em digestibilidade e teor de energia metabolizável. A farinha de vísceras de frango, dentre as proteínas de origem animal secas demonstra-se como a de melhor digestibilidade e energia metabolizável.

Palavras chave: amido, canino, digestibilidade, felino, ingredientes, nutrição.

\section{Protein and carbohydrate ingredients for dogs and cats}

SUMMARY: Although Pet food companies use important amounts of protein and carbohydrate sources, little scientific information was published about digestibility and metabolizable energy of these ingredients for dogs and cats. Rice and corn have been considered the better starch sources for these animals, but it was presented that sorghum is well digestible for dogs too. When interpreting scientific data the reader needs to consider the differences among studies that evaluated flour or refined starch or the usage of ground grain, as employed by pet food companies. Besides of digestibility and energy content, starch interferes on dogs glycemic response's, which presents an opportunity to select low insulin and glucose response starch sources to diets designed to animals in special conditions. Due to high protein requirements, these ingredients are important in food formulation for dogs and cats. Protein sources of animal origin have greater variation in chemical composition, quality and digestibility than vegetable proteins. Animals' meals can have high levels of ash, limiting the inclusion of these ingredients in pet food formulation. On the other hand vegetable proteins can have antinutritional factors that must be inactivated during manufacturing. It was demonstrated that vegetable proteins can have good digestibility and metabolizable energy for dogs and cats. Their utilization in food formulation can help in reduction of diet' ash level, control of food's base excess and keeping good diet digestibility. Micronized whole soybean and corn gluten meal with $60 \%$ protein are highlighted, showing good digestibility and energy content's values for dogs and cats. In relation to dry animal proteins, poultry by product meal have better digestibility and metabolizable energy values.

Key word: canine, digestibility, feline, ingredient, nutrition, starch.

\section{Introdução}

Estima-se, no Brasil, um crescimento de $667 \%$ na produção de alimentos industrializados para cães e gatos nos últimos 10 anos. Segundo dados da Associação Nacional dos Fabricantes de Alimentos para Animais de Estimação (Anfalpet, 2007), em 2006, a produção nacional de ração para animais de companhia 
foi de 1.687.404 toneladas, um crescimento de $8 \%$ em relação ao ano anterior, com movimentação de dois bilhões de reais. Este crescimento teve suporte em avanços científicos e tecnológicos, no aprimoramento do processo de produção em larga escala e na disponibilidade de matérias primas, especialmente os subprodutos de origem animal.

Vê-se no mundo uma explosão do número de marcas de dietas comerciais prontas para o consumo, com formulações cada vez mais sofisticadas e específicas (Steiff \& Bauer, 2001). Estabeleceu-se, com isto, elevada competitividade, o que tem levado à segmentação de produtos que apresentam padrões comerciais e nutricionais distintos. As empresas, de um lado, têm desenvolvido produtos específicos, com o intuito de chamar a atenção do consumidor para um alimento diferenciado e de elevado valor nutricional, com conseqüente maior custo. Estes apresentam formulação mais sofisticada, com o emprego de ingredientes selecionados e melhor processamento. Por outro lado, também são produzidos alimentos econômicos, de baixo valor agregado e que competem no mercado apenas por preço, sendo formuladas com ingredientes mais baratos. Desta forma, o mercado pet absorve hoje ampla gama de ingredientes e subprodutos, empregados na produção de alimentos variados, com densidades nutricionais e digestibilidades distintas.

Ao lado desta expansão e sofisticação do mercado, um levantamento dos dados científicos disponíveis sobre nutrição e, principalmente, sobre alimentos para cães e gatos, demonstra uma surpreendente escassez de informações. Apesar de se registrar progresso no conhecimento a cerca das necessidades nutricionais de cães e gatos (NRC, 2006), são necessárias informações mais precisas sobre quase todos os nutrientes. Não se conhece, tampouco, as biodisponibilidades dos nutrientes nos alimentos empregados nas formulações (Bontempo, 2005), o que faz com que, via de regra, as formulações sejam baseadas nos nutrientes brutos, não nos disponíveis. Não se dispõem de tabelas de composição dos alimentos para cães e gatos que apresentem estimativas de nutrientes digestíveis, como ocorre para suínos e aves, como exemplo em Rostagno, et al. (2005).

\section{Fontes de carboidrato para cães e gatos}

Na maioria das rações extrusadas para cães e gatos, os amidos constituem a maior fonte de energia (Cheeke, 1999). Podem representar de 40 a 55\% da matéria seca destes alimentos (Kronfeld, 1975), fornecendo de $30 \%$ a $60 \%$ de sua energia metabolizável. Suas características nutritivas dependem da composição dos seus açúcares, de seus tipos de ligação química, de fatores físico-químicos de digestão (Van Soest, 1994) e de seu processamento (Holste et al., 1989; Wolter et al., 1998).

Apesar de sua suscetibilidade à ação enzimática dos monogástricos, há uma porção do amido que é resistente à hidrólise. Sua digestibilidade é afetada por sua forma física, interações entre proteína e amido, integridade de seus grânulos e pela presença de fatores antinutricionais, como o tanino (Rooney \& Pflugfelder, 1986). As razões para a digestão incompleta do amido podem ser separadas em fatores intrínsecos e extrínsecos (Englyst et al., 1992). Dentre os fatores intrínsecos incluem-se: inacessibilidade física do amido; resistência dos grânulos à ação enzimática; formação de amido retrogradado. A inacessibilidade física ocorre quando o amido encontra-se contido em uma estrutura celular, como grãos e sementes integrais ou parcialmente moídas, sendo inacessíveis à ação enzimática. A resistência do grânulo depende da sua composição em amilopectina e amilose e de sua estrutura cristalina. A estrutura cristalina é classificada de acordo com a difração aos raios-X, em formas A, B e C. Os grânulos nas formas $\mathrm{B}$ e $\mathrm{C}$ são mais resistentes à ação enzimática do que os grânulos na forma A. O amido retrogradado é formado durante o resfriamento do amido gelatinizado, ocorrendo sua recristalização nas formas B e C, mais resistentes à digestão (Englyst \& Cummings, 1990; Annison \& Topping, 1994; Englyst et al., 1996; Lobo \& Silva, 2003).

Os fatores extrínsecos que influenciam a digestibilidade do amido no intestino delgado são: tempo de trânsito intestinal, concentração de amilase disponível para a quebra do amido e a presença de outros componentes da dieta que retardem a hidrólise enzimática (Englyst \& Cummings, 1990; Englyst et al., 2003).

O processamento do amido, incluindo sua moagem e cozimento durante o processo de extrusão, é fundamental para aumentar sua digestibilidade para os carnívoros (Murray et al., 2001). Em relação ao tamanho das partículas, têm-se como regra geral que quanto mais finamente moído, melhor a digestibilidade, mas isto não é sempre verdadeiro, como será discutido adiante. Meyer (1997) relata que a digestibilidade do amido varia conforme a fonte e o processamento da matéria prima. Assim, apesar dos amidos de arroz e trigo apresentarem digestão acima de $97 \%$ mesmo sem tratamento algum, para apresentarem boa digestão (99\% e 100\%) pelos cães, o 
amido de milho precisa ser moído e micronizado e os amidos de batata e mandioca, cozidos. Wolter et al. (1998) compararam a digestibilidade de dois carboidratos em sua forma crua e gelatinizada. Demonstraram que o processo de gelatinização não foi importante para a digestibilidade ileal do amido de trigo, resultando em 99,4\% para o amido cru e 98,0\% para o gelatinizado. Contudo, para o amido de mandioca, a digestibilidade ileal aumento de 57,6\%, para o amido cru, para 97,4\%, para o gelatinização.

Murray et al. (1999) compararam a digestibilidade das farinhas de cevada, milho, batata, arroz, sorgo e trigo para cães. Os resultados demonstraram digestibilidade ileal do amido acima de 99\% para todas as fontes, mas a digestão da proteína, matéria orgânica, matéria seca e a qualidade das fezes variaram entre as dietas, destacando a importância da fonte de amido sobre a digestão geral da ração. Mesmo entre cultivares de um mesmo grão existem diferenças quanto à digestibilidade do amido. Estudando o arroz, Belay et al. (1997) demonstraram menor digestibilidade para o arroz de grão longo, devido à sua maior proporção de amilose.

Carciofi, et al. (2008) estudaram, em dietas isonutrientes, seis fontes de amido para cães. A diferença entre este estudo e os anteriormente citados é que, neste, foram empregados grãos inteiros ou farinhas integrais, da forma como são empregados pela indústria, enquanto que nos experimentos anteriores foram empregados amidos puros ou farinhas refinadas. As farinhas de grãos são constituídas basicamente por amido e proteína, ao passo que a constituição dos grãos moídos, mais rotineiramente empregados nas rações, inclui o pericarpo, o germe e a aleurona, que conferem lípides, fibras e cinzas (Hoseney, 1994), tornando as vezes difícil a extrapolação dos resultados para situações práticas. A fibra, presente nos grãos integrais, é também um nutriente importante e que necessita ser avaliado, pois esta interfere na digestão do alimento (Burrows, et al., 1982, Fahey et al., 1990a; Fahey et al., 1990b).

Foram determinados os coeficientes de digestibilidade aparente e as respostas glicêmicas e insulínicas pós-prandiais desencadeadas por dietas nas quais o ingrediente amiláceo em estudo correspondia de 42,5\% (farinha de mandioca) a 69,5\% da fórmula (lentilha). Os coeficientes de digestibilidade verificados para as dietas encontram-se na tabela 1.

Tabela 1 - Coeficientes de digestibilidade aparente (média \pm erro padrão da média) de dietas com diferentes fontes de amido para cães.

Table 1. Apparent digestibility coefficients (mean \pm standard error) of foods with different starch sources for dogs.

\begin{tabular}{|c|c|c|c|c|c|c|}
\hline \multirow{4}{*}{$\begin{array}{l}\text { Nutriente }^{1} \\
\text { Nutrient }\end{array}$} & \multicolumn{6}{|c|}{$\begin{array}{l}\text { Dietas experimentais } \\
\text { Experimental foods }\end{array}$} \\
\hline & Mandioca & Milho & Sorgo & Arroz & Lentilha & Ervilha \\
\hline & Cassava & Corn & Sorghum & Rice & Lentil & Pea \\
\hline & \multicolumn{6}{|c|}{$\begin{array}{l}\text { Coeficientes de digestibilidade aparente } \\
\text { Apparent digestibility coefficients }\end{array}$} \\
\hline $\begin{array}{l}\text { MS } \\
D M\end{array}$ & $83,09^{a} \pm 0,04$ & $78,58^{\mathrm{b}} \pm 0,50$ & $79,02^{\mathrm{b}} \pm 0,32$ & $82,36^{\mathrm{a}} \pm 0,17$ & $74,53^{\mathrm{C}} \pm 0,60$ & $76,06^{\mathrm{c}} \pm 0,73$ \\
\hline $\begin{array}{l}\text { MO } \\
O M\end{array}$ & $87,70^{a} \pm 0,07$ & $83,93^{\mathrm{b}} \pm 0,49$ & $83,78^{b} \pm 0,25$ & $88,45^{a} \pm 0,23$ & $79,31^{\mathrm{c}} \pm 0,44$ & $80,09^{c} \pm 0,79$ \\
\hline $\begin{array}{l}\mathrm{PB} \\
C P\end{array}$ & $86,76^{\mathrm{ab}} \pm 0,50$ & $86,14^{b} \pm 0,35$ & $85,04^{\mathrm{bc}} \pm 0,56$ & $89,03^{a} \pm 0,59$ & $79,91^{d} \pm 0,72$ & $83,38^{\mathrm{C}} \pm 0,63$ \\
\hline $\begin{array}{l}\text { EEA } \\
\text { AHF }\end{array}$ & $92,76^{a} \pm 0,26$ & $89,12^{\mathrm{bc}} \pm 0,39$ & $88,28^{\mathrm{c}} \pm 0,17$ & $88,98^{\mathrm{bc}} \pm 0,46$ & $89,37^{\mathrm{bc}} \pm 0,51$ & $90,04^{\mathrm{b}} \pm 0,28$ \\
\hline $\begin{array}{l}\text { FDT } \\
\text { TDF }\end{array}$ & $8,23^{\mathrm{C}} \pm 2,28$ & $11,44^{\mathrm{c}} \pm 3,35$ & $26,96^{\mathrm{ab}} \pm 1,40$ & $17,75^{\mathrm{bc}} \pm 0,76$ & $33,44^{\mathrm{a}} \pm 1,70$ & $30,30^{a} \pm 3,05$ \\
\hline $\begin{array}{l}\text { AMIDO } \\
\text { Starch }\end{array}$ & $99,37^{a} \pm 0,05$ & $99,09^{\mathrm{ab}} \pm 0,07$ & $99,06^{\mathrm{ab}} \pm 0,07$ & $99,33^{\mathrm{a}} \pm 0,01$ & $98,80^{b} \pm 0,20$ & $98,69^{b} \pm 0,13$ \\
\hline $\begin{array}{l}\mathrm{EB} \\
\mathrm{CE}\end{array}$ & $87,76^{a} \pm 0,13$ & $84,87^{\mathrm{b}} \pm 0,64$ & $84,21^{b} \pm 0,47$ & $87,75^{a} \pm 0,47$ & $78,39^{d} \pm 0,52$ & $80,95^{\mathrm{c}} \pm 0,84$ \\
\hline
\end{tabular}

1- Nutriente: MS - matéria seca; MO - matéria orgânica; PB - proteína bruta; EEA - extrato etéreo hidrólise ácida; FDT - fibra dietética total; EBenergia bruta. Nutrients: DM - dry matter; OM - organic matter; CP - crude protein; AHF - acid hidrolized fat; TDF - total dietary fiber; CE - crude energy.

$\mathrm{a}, \mathrm{b}, \mathrm{c}, \mathrm{d}$ - Médias na mesma linha sem uma letra em comum são estatisticamente diferentes pelo teste de Tukey (p< 0,05). Retirado de Carciofi, et al. (2008). a, b, c, d - Means in the same row not sharing a common letter differ by Tukey test ( $p<0.05)$. Based on Carciofi et al. (2008). 
De-Oliveira (2005) avaliou os mesmos ingredientes para gatos. As formulações foram próximas, variando os ingredientes em estudo de $40 \%$ (farinha de mandioca) a 66\% da formula (lentilha). Os coeficientes de digestibilidade verificados para as dietas encontram-se na tabela 2.

Tabela 2 - Coeficientes de digestibilidade aparente (média erro padrão da média) mediante o consumo de dietas com diferente fontes de amido por gatos. Table 2: Apparent digestibility coefficient (mean \pm standard error) of foods with different starch sources for cats

\begin{tabular}{|c|c|c|c|c|c|c|}
\hline \multirow{2}{*}{$\begin{array}{c}\text { Nutriente }^{1} \\
\text { Nutrient }\end{array}$} & \multicolumn{6}{|c|}{$\begin{array}{c}\text { Dietas } \\
\text { Experimental foods }\end{array}$} \\
\hline & $\begin{array}{l}\text { Mandioca } \\
\text { Cassava }\end{array}$ & $\begin{array}{l}\text { Milho } \\
\text { Corn }\end{array}$ & $\begin{array}{l}\text { Sorgo } \\
\text { Sorghum }\end{array}$ & $\begin{array}{c}\text { Arroz } \\
\text { Rice }\end{array}$ & $\begin{array}{l}\text { Lentilha } \\
\text { Lentil }\end{array}$ & $\begin{array}{l}\text { Ervilha } \\
\text { Pea }\end{array}$ \\
\hline & \multicolumn{6}{|c|}{$\begin{array}{c}\text { Coeficientes de digestibilidade aparente (\%) } \\
\text { Apparent digestibility coefficient }\end{array}$} \\
\hline $\begin{array}{l}\text { MS } \\
D M \\
\text { MO }\end{array}$ & $80,28^{a b} \pm 0,64$ & $78,50^{\mathrm{bc}} \pm 0,33$ & $76,33^{\mathrm{bc}} \pm 0,52$ & $83,22^{\mathrm{a}} \pm 1,11$ & $76,48^{\mathrm{bc}} \pm 1,72$ & $75,89^{\mathrm{c}} \pm 1,00$ \\
\hline $\begin{array}{l}O M \\
\mathrm{~PB}\end{array}$ & $84,32^{\mathrm{ab}} \pm 0,63$ & $82,46^{\mathrm{bc}} \pm 0,37$ & $79,97^{\mathrm{c}} \pm 0,54$ & $87,86^{a} \pm 0,59$ & $78,99^{\mathrm{c}} \pm 1,66$ & $79,10^{\mathrm{C}} \pm 1,00$ \\
\hline $\begin{array}{c}C P \\
\text { Amido }\end{array}$ & $81,99^{b} \pm 0,88$ & $83,25^{b} \pm 0,55$ & $80,64^{b} \pm 0,63$ & $87,73^{\mathrm{a}} \pm 1,28$ & $80,84^{b} \pm 1,61$ & $82,26^{b} \pm 0,72$ \\
\hline $\begin{array}{l}\text { Starch } \\
\text { EEA }\end{array}$ & $97,97^{\mathrm{ab}} \pm 0,32$ & $97,55^{\mathrm{ab}} \pm 0,41$ & $93,95^{d} \pm 0,65$ & $98,62^{\mathrm{a}} \pm 0,29$ & $95,22^{\mathrm{dc}} \pm 0,67$ & $96,31^{\mathrm{bc}} \pm 0,38$ \\
\hline $\begin{array}{l}\text { AHF } \\
\mathrm{EB}\end{array}$ & $89,59^{a} \pm 0,82$ & $85,46^{\mathrm{bc}} \pm 0,51$ & $83,27^{\mathrm{c}} \pm 0,55$ & $87,79^{\mathrm{ab}} \pm 1,35$ & $85,35^{\mathrm{bc}} \pm 0,85$ & $87,97^{\mathrm{ab}} \pm 0,81$ \\
\hline $\begin{array}{l}C E \\
\text { FDT }\end{array}$ & $84,21^{\mathrm{ab}} \pm 0,67$ & $82,56^{\mathrm{bc}} \pm 0,34$ & $79,56^{c} \pm 0,50$ & $87,57^{\mathrm{a}} \pm 0,72$ & $80,11^{\mathrm{c}} \pm 1,58$ & $80,50^{\mathrm{bc}} \pm 0,88$ \\
\hline$T D F$ & $5,61^{b} \pm 5,96$ & $18,09^{\mathrm{ab}} \pm 2,12$ & $29,03^{\mathrm{ab}} \pm 3,04$ & $10,63^{\mathrm{ab}} \pm 7,90$ & $33,11^{\mathrm{a}} \pm 5,66$ & $15,82^{\mathrm{ab}} \pm 5,86$ \\
\hline
\end{tabular}

1. Nutriente: MS - matéria seca; MO - matéria orgânica; PB - proteína bruta; EEA - extrato etéreo hidrólise ácida; FDT - fibra dietética total; EBenergia bruta. Nutrients: DM - dry matter; OM - organic matter; CP - crude protein; AHF - acid hidrolized fat; TDF - total dietary fiber; CE - crude energy.

a, b, c, d - Médias na mesma linha sem uma letra em comum são estatisticamente diferentes pelo teste de Tukey ( $\mathrm{p}<0,05)$. Retirado de deOliveira (2005). ${ }^{a, b, c, d}$ - Means in the same row not sharing a common letter differ by Tukey test ( $\left.p<0.05\right)$. Based on de-Oliveira (2005).

Pode-se observar que tanto para os cães como para os gatos as dietas com quirera de arroz e farinha de mandioca apresentaram os maiores coeficientes de digestibilidade da MS, MO e EB, além do EEA para os gatos $(p<0,05)$. Estas foram seguidas pelas dietas com milho e sorgo pelos cães e milho e ervilha pelos gatos $(\mathrm{p}<0,05)$. Por último, com os menores valores de digestibilidade, tem-se a ervilha e a lentilha para os cães e a lentilha e o sorgo para os gatos $(\mathrm{p}<0,05)$. As dietas com quirera de arroz apresentaram as maiores digestibilidades da proteína, tanto para cães como para gatos $(p<0,05)$. Interferiram negativamente na digestibilidade de proteína a lentilha e a ervilha para cães. Para gatos as demais dietas apresentaram resultados semelhantes. As dietas com sorgo, ervilha e lentilha apresentam maiores CD da fibra dietética total para os cães. Para gatos houve menor variação na digestibilidade deste nutriente. Sorgo, milho e arroz já haviam sido avaliados para cães por Twomey et al. (2002), Twomey et al. (2003) e Silva Jr et al. (2005), com resultados semelhantes ao verificado por Carciofi, et al. (2008).

Quanto à qualidade das fezes produzidas, as dietas com milho, sorgo e quirera de arroz levaram os cães a produzirem fezes com menor teor de água e maior $\mathrm{pH}$, o que indica menor fermentação no intestino grosso. Para os gatos a dieta com arroz levou à produção de fezes com menor teor de água, sendo esta semelhante à da dieta com milho, que por sua vez não diferiu das demais.

Destaca-se a menor digestibilidade do sorgo observada para os gatos, em relação aos demais amidos. Esse fato talvez se explique por uma possível menor tolerância dos gatos ao tanino do sorgo, que nas dietas era de $0,57 \%$. Entretanto, essa mesma quantidade de tanino não parece ter influenciado a digestibilidade pelos cães, já que o sorgo teve digestibilidade semelhante a do milho. Murray et al. (1999), quando avaliaram a digestibilidade das farinhas de arroz, milho e sorgo, observaram que a digestibilidade desta última 
foi inferior a das farinhas de milho e arroz. Além disso, também já foi observado que a digestibilidade de arroz supera a do milho (Belay et al., 1997; Walker et al. 1994). Os coeficientes de digestibilidade do arroz e da farinha da mandioca se mostraram bastante próximos, tanto para cães quanto para gatos, corroborando com os dados obtidos por Kamalu (1991).

Todos os ingredientes estudados apresentaram altos coeficientes de digestibilidade do amido, com valores superiores a $98,5 \%$ para os cães e $94 \%$ para os gatos. Nota-se que mesmo felinos podem digerir adequadamente ingredientes amiláceos, desde que estes estejam adequadamente processados.

Estudando a digestibilidade do ingrediente, não da dieta, Sa-Fortes (2006) empregou o método de substituição. Os coeficientes de digestibilidade e os valores de energia metabolizável dos ingredientes estão, respectivamente, nas tabelas 3 e 4 . Esta verificou que, de uma maneira geral, os cães aproveitaram melhor os nutrientes do milho, sorgo, quirera de arroz e milheto. Resultados semelhantes foram verificados por Twomey et al. (2002) e Carciofi, et al. (2008). A menor concentração de fibra dietética total destes ingredientes pode estar relacionada com seu melhor aproveitamento pelos cães.

Os polissacarídeos não amiláceos (PNA), como os arabinoxilanos, $\beta$-glucanos e $\alpha$-galactosídeos estão presentes em diferentes concentrações nos cereais (Annison, 1991). O principal efeito relacionado aos PNA, segundo Choct \& Annison (1992) é o aumento da viscosidade intestinal devido à formação de polímeros com água, comprometendo a digestibilidade dos nutrientes. Este efeito, segundo os autores, está principalmente relacionado às frações solúveis destes compostos, que se apresentam em maior quantidade nos farelos de arroz e trigo.

Tabela 3 - Coeficiente de digestibilidade aparente da matéria seca (CDMS), proteína bruta (CDPB), matéria orgânica (CDMO), extrato etéreo ácido (CDEEA), amido (CDAMIDO) e fibra dietética total (CDFDT) de fontes de carboidratos para cães (média \pm erro padrão da média) Table3. Apparent digestibility coefficient (mean \pm standard error) of dry matter (CADDM), crude protein (CADCP), organic matter (CADOM), acid hidrolized fat (CADAHF), starch (CADSTARCH)) and total dietary fiber (CADTDF) of different carbohydrate sources for dogs.

\begin{tabular}{|c|c|c|c|c|c|c|}
\hline $\begin{array}{l}\text { Ingredientes } \\
\text { Ingredients }\end{array}$ & $\begin{array}{l}\text { CDMS } \\
C A D D M\end{array}$ & $\begin{array}{l}\text { CDPB } \\
C A D C P \\
\end{array}$ & $\begin{array}{l}\text { CDMO } \\
\text { CADOM }\end{array}$ & $\begin{array}{l}\text { CDEEA } \\
\text { CADAHF }\end{array}$ & $\begin{array}{c}\text { CDAMIDO } \\
\text { CADSTARCH }\end{array}$ & $\begin{array}{l}\text { CDFDT } \\
\text { CADTDF }\end{array}$ \\
\hline $\begin{array}{l}\text { Milheto } \\
\text { Millet }\end{array}$ & $85,9 \pm 1,3^{\mathrm{a}}$ & $80,3 \pm 2,1^{\mathrm{a}}$ & $87,4 \pm 1,3^{\mathrm{a}}$ & $82,1 \pm 1,2^{\mathrm{ab}}$ & $99,1 \pm 0,3^{\mathrm{a}}$ & $65,5 \pm 8,2^{a}$ \\
\hline $\begin{array}{l}\text { Quirera de Arroz } \\
\text { Brewers rice }\end{array}$ & $90,5 \pm 1,6^{a}$ & $75,3 \pm 1,7^{\mathrm{bc}}$ & $90,9 \pm 1,5^{\mathrm{a}}$ & $66,8 \pm 5,0^{c}$ & $99,2 \pm 0,2^{\mathrm{a}}$ & $73,9 \pm 5,8^{a}$ \\
\hline $\begin{array}{l}\text { Gérmen de Milho } \\
\text { Corn germ }\end{array}$ & $65,5 \pm 1,5^{b}$ & $65,6 \pm 1,4^{\mathrm{d}}$ & $66,6 \pm 1,6^{b}$ & $48,2 \pm 2,2^{\mathrm{d}}$ & $95,5 \pm 0,4^{b}$ & $23,4 \pm 5,0^{\circ}$ \\
\hline $\begin{array}{l}\text { Sorgo } \\
\text { Sorghum }\end{array}$ & $90,5 \pm 0,98^{\mathrm{a}}$ & $88,4 \pm 1,4^{a}$ & $89,6 \pm 0,8^{\mathrm{a}}$ & $78,6 \pm 2,7^{\mathrm{b}}$ & $98,7 \pm 0,3^{\mathrm{a}}$ & $73,6 \pm 8,5^{a}$ \\
\hline $\begin{array}{l}\text { Farelo de Trigo } \\
\text { Wheat bran }\end{array}$ & $59,3 \pm 1,9^{c}$ & $68,2 \pm 2,6^{\mathrm{cd}}$ & $55,4 \pm 1,2^{c}$ & $53,8 \pm 2,7^{\mathrm{d}}$ & $89,6 \pm 1,3^{\mathrm{c}}$ & $20,2 \pm 3,5^{c}$ \\
\hline $\begin{array}{l}\text { Milho } \\
\text { Corn }\end{array}$ & $89,3 \pm 1,2^{\mathrm{a}}$ & $88,4 \pm 3,7^{\mathrm{a}}$ & $87,1 \pm 1,1^{\mathrm{a}}$ & $83,0 \pm 2,6^{\mathrm{ab}}$ & $98,5 \pm 0,3^{\mathrm{a}}$ & $50,1 \pm 4,6^{\mathrm{ab}}$ \\
\hline $\begin{array}{l}\text { Farelo de Arroz } \\
\text { Rice bran }\end{array}$ & $55,0 \pm 1,9^{c}$ & $72,9 \pm 2,9^{\text {bcd }}$ & $58,9 \pm 1,1^{\mathrm{c}}$ & $85,2 \pm 1,0^{\mathrm{ab}}$ & $90,4 \pm 0,6^{c}$ & $11,7 \pm 2,0^{\circ}$ \\
\hline
\end{tabular}

a, b, c, d- Médias nas colunas seguidas de letras iguais não diferem entre si pelo teste Student Newman Kewls ( $\mathrm{p}<0,05)$. Retirado de Sa Fortes (2006). ${ }^{a, b}, c, d-M e a n s$ in the same column sharing a common letter do not differ by Student Newman Kewls ( $\left.p<0,05\right)$. Based on Sa Fortes (2006). 
Tabela 4 - Valores de energia bruta (EB), energia metabolizável (EM) e coeficientes de metabolização da energia bruta (CMEB) de fontes de carboidratos para cães (média \pm erro padrão da média). Table 4. Gross energy (GE), metabolizable energy (ME) and gross energy metabolization coefficient (GEMC) of carbohydrate souces for dogs (mean \pm standard error).

\begin{tabular}{lccc}
\hline \multicolumn{1}{c}{ Ingredientes } & EB & EM & CMEB \\
Ingredients & $G E$ & $36 E C$ & $72,7 \pm 2,0 \mathrm{~b}$ \\
\hline $\begin{array}{l}\text { Milheto } \\
\text { Millet }\end{array}$ & 4963,9 & $3537,6 \pm 76,9 \mathrm{~b}$ & $82,5 \pm 1,8 \mathrm{a}$ \\
$\begin{array}{l}\text { Quirera de Arroz } \\
\text { Breweres rice } \\
\text { Gérmen de Milho }\end{array}$ & 4288,5 & $2421,7 \pm 127,9 \mathrm{~d}$ & $56,4 \pm 3,0 \mathrm{c}$ \\
Corn germ & 4292,1 & $3580,5 \pm 63,1 \mathrm{~b}$ & $79,5 \pm 1,4 \mathrm{ab}$ \\
$\begin{array}{l}\text { Sorgo } \\
\text { Sorghum }\end{array}$ & 4506,7 & $2419,7 \pm 105,8 \mathrm{~d}$ & $58,8 \pm 2,6 \mathrm{c}$ \\
$\begin{array}{l}\text { Farelo de Trigo } \\
\text { Wheat bran } \\
\text { Milho }\end{array}$ & 4114,9 & $3903,9 \pm 100,7 \mathrm{a}$ & $86,0 \pm 2,2 \mathrm{a}$ \\
$\begin{array}{l}\text { Corn } \\
\text { Farelo de Arroz } \\
\text { Rice bran }\end{array}$ & 4541,1 & $3146,9 \pm 54,2 \mathrm{c}$ & $62,8 \pm 1,1 \mathrm{c}$ \\
\hline
\end{tabular}

a, b, c, d - Médias nas colunas seguidas de letras iguais não diferem entre si pelo teste Student Newman Kewls (5\%), Retirado de Sa Fortes (2006). ). a, b, c, d - Means in the same column sharing a common letter do not differ by Student Newman Kewls ( $p<0,05)$. Based on Sa Fortes (2006).

Apesar de amplamente estabelecido que o processamento do amido, incluindo moagem e gelatinização, é fundamental ao aproveitamento deste nutriente (Fadel et al., 1988; Owsley et al., 1981), não foram localizados artigos científicos que tenham estudado a influência da redução de partículas sobre a digestibilidade de alimentos extrusados para cães ou gatos.

Em função disto foi conduzido por Bazolli (2007) estudo que avaliou a influência do grau de moagem do arroz, do milho e do sorgo sobre a digestibilidade e respostas metabólicas em cães. Foi empregado arroz com diâmetro geométrico médio (DGM) de $277 \mu \mathrm{m}, 311 \mu \mathrm{m}$ e $521 \mu \mathrm{m}$, milho com $360 \mu \mathrm{m}, 451 \mu \mathrm{m}$ e $619 \mu \mathrm{m}$ e sorgo com $314 \mu \mathrm{m}$, $439 \mu \mathrm{m}$ e $594 \mu \mathrm{m}$. A digestibilidade da MS e EB não variou entre os ingredientes $(p>0.05)$. A digestibilidade da PB, EEA e do amido foi maior para as dietas com arroz em relação às com sorgo $(\mathrm{p}<0.01)$. O DGM não afetou a digestibilidade das dietas com arroz, exceto para a digestibilidade da energia, com resposta linear positiva $(\mathrm{p}<0.01)$. Já o DGM do sorgo, bem como seu índice de gelatinização, apresentou resposta linear positiva para todos os nutrients $(\mathrm{p}<0.01)$, quanto menor a tamanho da partícula e maior sua gelatinização, maior a digestibilidade. Para as dietas com milho foi encontrada resposta quadrática na digestibilidade da maioria dos nutrientes $(\mathrm{p}<0.05)$. As digestibilidades da MS e PB estão ilustradas nas figuras 1 e 2 . As concentrações fecais de ácido butírico, lático e ácidos graxos de cadeia curta totais foram menores nas dietas com arroz $(\mathrm{p}<0.05)$. O aumento do DGM resultou em redução do acetato e propionado e em aumento no butirato nas fezes dos cães que receberam as dietas com sorgo $(\mathrm{p}<0.05)$. Desta forma, pôde-se concluir que para o milho e o sorgo, a redução do DGM pode aumentar a digestibilidade e melhorar a qualidade das fezes de cães e gatos, enquanto para o arroz o DGM não interferiu nestes aspectos (Bazolli, et al., 2007).

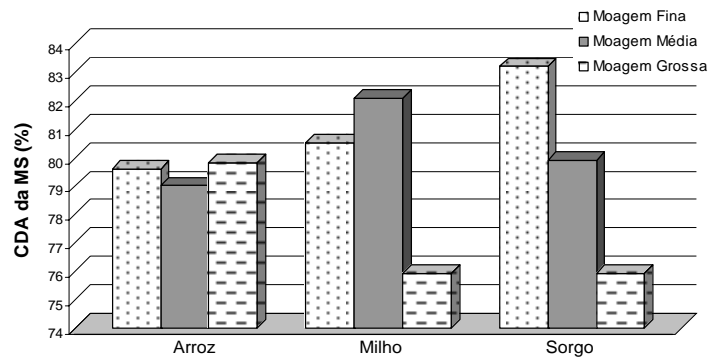

Figura 1 - Representação gráfica dos valores médios dos coeficientes de digestibilidade aparente (CDA) da matéria seca (MS) das nove dietas experimentais pelos cães (Bazolli, 2007). Figure 1. Illustration of mean apparent digestibility coefficient of dry matter of the experimental diets varying in starch source and particle size to dogs (Bazolli, 2007). 


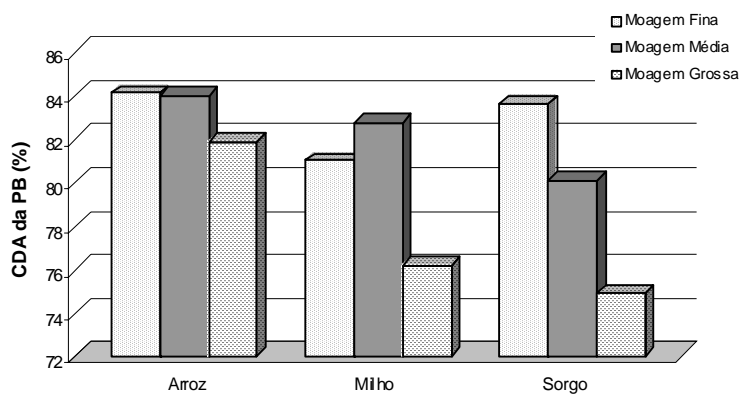

Figura 2. Representação gráfica dos valores médios dos coeficientes de digestibilidade aparente (CDA) da proteína bruta (PB) das dietas experimentais pelos cães (Bazolli, 2007). Figure 2. Illustration of mean apparent digestibility coefficient of crude protein of the experimental diets varying in starch source and particle size to dogs (Bazolli, 2007)

Por fim, deve-se considerar que o amido é o principal nutriente que altera e determina a onda pósprandial de glicose sanguínea e a resposta insulínica do animal (Milla et al., 1996; Sunvold et al., 1995; Sunvold, 1996; Appleton et al., 2004). Sendo assim, quanto mais rápida e completa sua digestão, mais rápida e intensa será a curva desencadeada (Jenkins et al., 1981), o que apresenta conseqüência metabólicas aos animais com reflexos em saúde a longo prazo e que, cada vez mais, vem sendo estudados e valorizados.

Deve-se considerar, no entanto, que além da natureza química dos amidos, especialmente suas proporções de amilose e amilopectinas (Behall et al., 1988; Behall et al., 1989), outros fatores também influenciam a onda pós-prandial de glicose e insulina como proteína e gordura (Nuttall et al., 1984; Nguyen et al., 1994), fibra dietética (Nishimune et al., 1991) e o próprio processamento do alimento (Holste et al., 1989).

O controle glicêmico pode estar prejudicado em alguns estágios fisiológicos e condições de saúde, como diabetes mellitus, obesidade, gestação, estresse, infecção, câncer e idade avançada (Nelson et al., 1990; Kahn et al., 2001). Para animais nestas condições, a utilização de dietas que minimizem e estendam a onda glicêmica pós-prandial favorece o reestabelecimento mais rápido e fácil da glicemia (Brand-Miller, 1994; FAO, 1998; Bouchard \& Sunvold, 1999). Diferenças importantes na resposta glicêmica de cães sadios mediante o consumo de dietas isonutrientes com diferentes fontes de amido foram identificadas por
Carciofi et al. (2008), como ilustrado na figura 3, podendo ser empregadas para dietas específicas.

Aproximadamente 25\% à 40\% da matéria seca de alimentos premium para cães são provenientes de subprodutos de origem animal. Estes ingredientes foram os maiores contribuintes para o crescimento e expansão da indústria mundial de petfood, apresentando-se como importantes fontes de proteínas, gorduras e minerais na alimentação de cães e gatos (Murray et al., 1997).

De importância na avaliação qualitativa de um ingrediente protéico tem-se: sua digestibilidade e composição de aminoácidos, que se remetem ao seu valor biológico (Pond et al, 1995); sua relação proteína:cinzas, que é larga em ingredientes de origem animal e mais favorável nos ingredientes de origem vegetal (Cowell et al, 2000); e sua palatabilidade. Adicionalmente, a origem e o processamento a que estes ingredientes são submetidos são fatores determinantes para sua qualidade e digestibilidade (Johnson et al, 1998).

O uso de proteínas vegetais tem aumentado em produtos fabricados no Brasil, provavelmente, em função do bom desempenho de alimentos com composição protéica mista animal e vegetal, da redução da matéria mineral da dieta e do menor custo do alimento conseguidos com sua inclusão na fórmula. Estes se caracterizam por apresentar composição bromatológica com menor variação que os de origem animal, porém, em geral, apresentam limitação em aminoácidos sulfurados e triptofano (Lowe, 1989). Já as fontes animais possuem melhor balanço em aminoácidos essenciais. No entanto, sua qualidade nutricional está diretamente relacionada com a origem de suas matérias-primas e o processamento adotado (Bellaver, 2001).

Farinhas de origem animal apresentam grande variação em sua composição nutricional devido à variação de composição de matérias-primas e os efeitos de processamento, principalmente pressão, temperatura e tempo empregados, resultando em ingredientes com valores nutricionais bastante diferentes (Parsons et al., 1997). Os coeficientes de digestibilidade e a disponibilidade dos aminoácidos em farinhas de subprodutos de origem animal também são muito variáveis. Acredita-se que o teor de minerais e as características de processamento estejam diretamente envolvidos neste parâmetro (Johnson et al., 1998). 


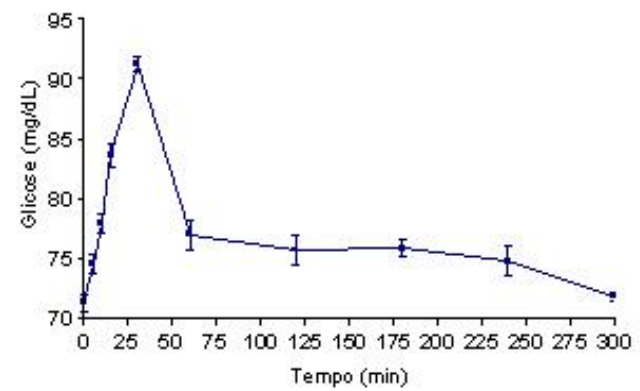

Figura 2: Curva glicêmica pós-prandial mediante consumo de dieta a base de farinha de mandioca (média \pm erro padrẫo da média).

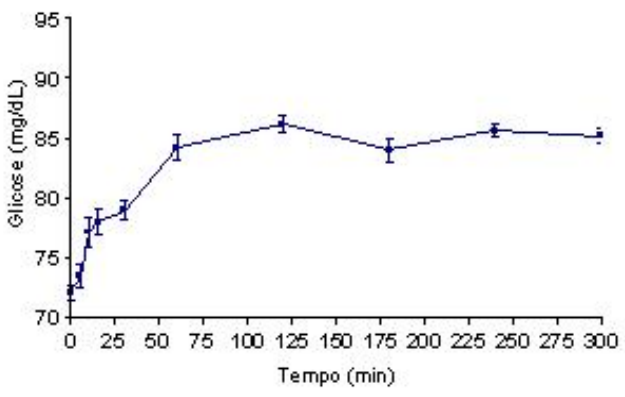

Figura 4: Curva glicêmica pós-prandial mediante consumo de dieta a base de sorgo (média \pm erro padrẫo da média).

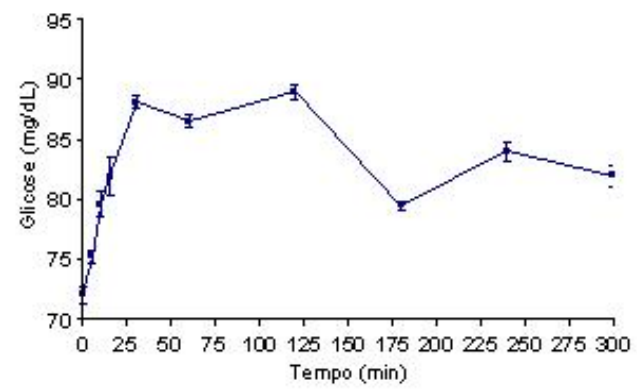

Figura 6: Curva glicêmica pós-prandial mediante consumo de dieta a base de lentilha (média \pm erro padrẫo da média).

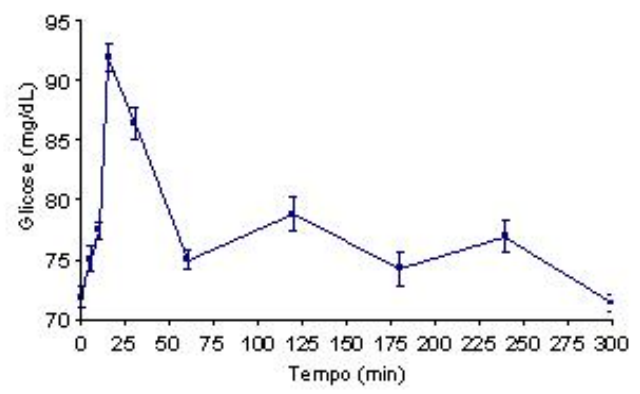

Figura 3: Curva glicêmica pós-prandial mediante consumo de dieta a base de milho (média \pm erro padrẫo da média).

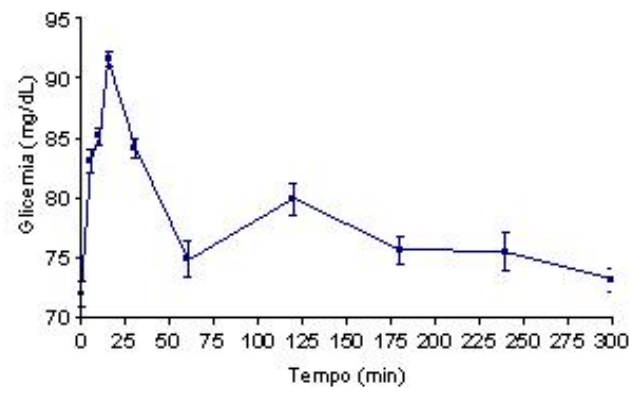

Figura 5: Curva glicêmica pós-prandial mediante consumo de dieta a base de quirera de arroz (média \pm erro padrẵo da média).

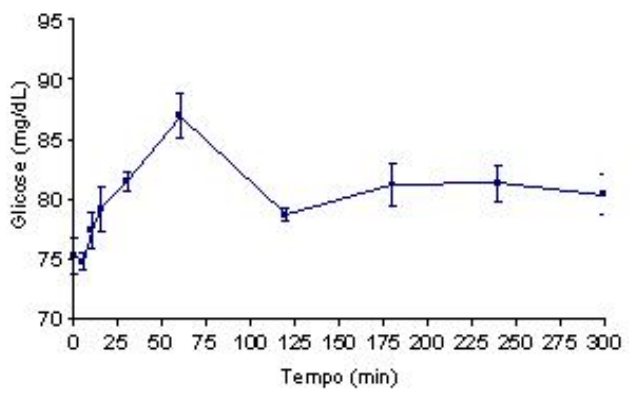

Figura 7: Curva glicêmica pós-prandial mediante consumo de dieta a base de ervilha (média \pm erro padrẫo da média).

Figura 3 - Curvas glicêmicas pós-prandiais de cães mediante o consumo de dietas com diferentes fontes de amido (Carciofi, et al., 2008)

Figure 3. Illustration of post prandials glycemic curves of dogs fed experimental diets varying in starch source (Carciofi et al, 2008). 


\section{Fontes de proteína para cães e gatos}

Vários autores (Johns et al., 1986; Wang \& Parsons, 1998) verificaram efeito negativo da temperatura elevada durante o processamento de proteínas animais sobre a digestibilidade de aminoácidos para animais de produção. Johnson et al., (1998) também verificaram menor coeficiente de digestibilidade de aminoácidos totais em dietas para cães contendo farinha de carne e ossos processada à $143^{\circ} \mathrm{C}$, em relação à processada a $129^{\circ} \mathrm{C}$. Em um dos poucos estudos que avaliaram o efeito do tratamento térmico em alimentos para felinos, Hendriks et al. (1999) empregaram alimentos úmidos com aproximadamente $60 \%$ de derivados cárneos. Por meio da determinação dos coeficientes de digestibilidade de aminoácidos em ratos, constataram que quanto maior o tempo no qual os alimentos foram submetidos à $121,1^{\circ} \mathrm{C}$, menor foi a digestibilidade dos aminoácidos. Ácido aspártico foi o aminoácido mais afetado, tendo sua digestibilidade caído de 78,3 para $40,2 \%$ após 24,2 minutos a $121,1^{\circ} \mathrm{C}$.

As fontes protéicas vegetais, por outro lado, apresentam composição mais uniforme, com menor variação entre partidas e fornecedores. No entanto, possuem fatores antinutricionais como inibidores de enzimas, lectinas, tanino, fitato, polissacarídeos não amiláceos, dentre outros, que quando presentes podem influenciar negativamente a disponibilidade de seus nutrientes. $\mathrm{O}$ tratamento térmico e industrial à que são submetidos, no entanto, pode reduzir e ou mesmo eliminar alguns destes fatores, melhorando significativamente a qualidade destas matérias-primas.

Carciofi, et al (2006) avaliaram quatro formulações para cães, cada uma contendo uma única fonte de proteína: farelo de soja, farelo de glúten de milho 60\%, farinha de vísceras de frango e farinha de carne e ossos. A fonte protéica em estudo representou 85\% da proteína da ração. Na figura 4 encontram-se ilustrados os coeficientes de digestibilidade encontrados para cada ração.

A dieta à base de farelo de soja apresentou o menor coeficiente de digestibilidade aparente da matéria seca, as dietas com farinha de carne e ossos e glúten de milho apresentaram valores intermediários e a farinha de vísceras de frango o maior valor $(\mathrm{p}<0,05)$. Retirando-se a interferência da matéria mineral, o coeficiente de digestibilidade aparente da matéria orgânica foi maior para a ração com farinha de carne e ossos, permanecendo, no entanto, a com farelo de soja com os menores resultados $(\mathrm{p}<0,05)$. As dietas compostas por fontes de proteína vegetal apresentaram maiores coeficiente de digestibilidade aparente da proteína bruta. O maior valor foi encontrado para a ração com glúten de milho, seguida pela com farelo de soja, apresentando a dieta à base de farinha de carne e ossos resultado intermediário, e a com farinha de vísceras de frango o menor valor $(\mathrm{p}<0,05)$.

A consistência e qualidade das fezes correlacionam-se com sua quantidade de água. Quanto mais água estas possuem, mais moles e mal formadas se tornam. Fezes com teor de água muito baixo, por outro lado, podem predispor à retenção fecal e distúrbios digestivos. A dieta com farinha de carne e ossos levou os animais a produzirem fezes com menor teor de água, o que pode ser explicado pelo alto coeficiente de digestibilidade aparente da matéria orgânica e pelo maior teor de matéria mineral deste ingrediente. As rações com glúten de milho e farinha de vísceras de frango levaram à produção de fezes com umidade intermediária e a com farelo de soja fezes com maior teor de água, o que pode ser decorrente do menor coeficiente de digestibilidade aparente da matéria orgânica e dos extrativos não nitrogenados desta última. O baixo teor de umidade das fezes dos cães que consumiram ração com farinha de carne e ossos devese, ao menos em parte, à baixa relação proteína bruta:matéria mineral do ingrediente. Esta relação é um bom indicativo da eficiência da matéria prima em fornecer proteína sem elevar a matéria mineral da ração, sendo atualmente bastante importante na formulação de alimentos secos para cães (Cowell et al, 2000). Ingredientes com excesso de matéria mineral levam à formulação de alimentos com excesso de cálcio, fósforo e magnésio, quando de origem animal; ou de sílica, quando de origem vegetal, não sendo compatíveis com a nutrição ótima do animal.

Na tabela 5 são apresentados os coeficiente de digestibilidade aparente da proteína bruta de diversas dietas experimentais para cães, com diferentes fontes protéicas, que puderam ser localizados em trabalhos científicos na literatura internacional. Trata-se, também, da digestibilidade das dietas, em protocolos com rações isonutrientes, e não da digestibilidade do ingrediente protéico em estudo. Pode-se notar a grande variação de resultados entre os diversos experimentos citados. 


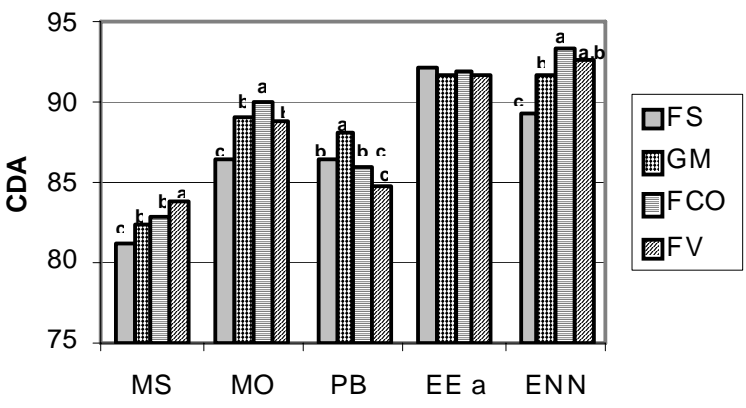

Figura 4 - Coeficientes de digestibilidade aparente das rações experimentais. Figure 4. Apparent digestibility coefficients of experimental diets.

a, b, c - médias de um mesmo nutriente sem uma letra em comum são diferentes pelo teste de Tukey $(p<0,05)$. FS- farelo de soja, GM - glúten de milho, FCO - farinha de carne e ossos, FV farinha de vísceras de frango. MS - matéria seca, MO - matéria orgânica, PB - proteína bruta, EEA - extrato etéreo hidrólise ácida, ENN - extrativos não nitrogenados (Carciofi, et al., 2006). ${ }^{\text {a, }}$

b, c - for each nutrient, means not sharing a common letter differ by Tukey test $(p<0.05)$. FS- soybean meal, GM - corn gluten meal, FCO - meat and bone meal, FV - poultry by products meal , MS dry matter, $\mathrm{MO}$ - organic matter, $\mathrm{PB}$ - crude protein, EEA - acid ether extract, ENN - nitrogen free extract (Carciofi et al, 2006).

A grande diferença de resultados entre experimentos observada para as farinhas de subprodutos de origem animal pode ser explicada por diferenças na composição e no processamento dos ingredientes. A farinha de carne e ossos pode apresentar diferentes inclusões de carne, ossos, couro e pêlos, enquanto a farinha de vísceras de frango pode apresentar diferentes proporções de cabeça, pescoço, pés, dorso, intestinos e até a inclusão indevida de penas. $O$ processamento das farinhas animais na graxaria, especificamente, a temperatura, a pressão e o tempo empregados, também pode comprometer a qualidade das mesmas, seja carbonizando matéria orgânica, diminuindo a digestibilidade total ou tornando aminoácidos específicos indisponíveis. Tais variações têm reflexo direto na qualidade protéica destes ingredientes, podendo haver grandes diferenças entre partidas e principalmente entre fornecedores destes subprodutos (Parsons, et al. 1997; Johnson et al. 1998).

Os produtos derivados da soja têm sido utilizados há muitos anos pela indústria de alimentos para cães e gatos, sendo o farelo de soja desengordurado, a farinha de soja e o grão integral os mais empregados em alimentos secos, e a proteína texturizada de soja a mais utilizada em alimentos úmidos (Case et al. 2000). O farelo de soja possui inúmeros fatores anti nutricionais, muitos dos quais são termolábeis, como os fatores inibidores de tripsina e quimiotripsina. $\mathrm{O}$ subprocessamento da soja mantém estes fatores ativos, prejudicando a performance do alimento. Desta forma, a baixa digestibilidade da PB do farelo de soja encontrada por Yanka et al. (2003b), entre 64,3 a 68,6\%, em comparação com outros estudos (Carciofi, et al, 2006; Clapper et al. 2001; Murray et al. 1997; Zuo et al, 1996), pode ser decorrente do emprego de um ingrediente mal processado. Segundo Yanka et al. (2003b), a baixa digestibilidade encontrada em seu experimento pode ter sido resultante do alto teor de estaquiose presente no farelo de soja utilizado (112g de estaquiose por quilograma farelo de soja). Entretanto, Zuo et al. (1996) não encontraram diferenças significativas ao estudar a digestibilidade do farelo de soja convencional e do farelo de soja com baixos teores de oligossacarídeos.

Tabela 5 - Coeficientes de digestibilidade aparente da proteína bruta de dietas extrusadas para cães, com diferentes fontes principais de proteína, encontrados em diferentes estudos disponíveis na literatura científica. Table 5: Coefficients of apparent digestibility of crude protein of extruded diets for dogs, with different main protein sources, available in different scientific publications

\begin{tabular}{|c|c|c|c|c|}
\hline \multirow[b]{2}{*}{$\begin{array}{l}\text { Autor } \\
\text { Author }\end{array}$} & \multicolumn{4}{|c|}{$\begin{array}{l}\text { Principal fonte protéica do alimento extrusado } \\
\text { Main protein source on extruded food }\end{array}$} \\
\hline & $\begin{array}{c}\text { Farelo de } \\
\text { soja } \\
\text { Soybean } \\
\text { Meal }\end{array}$ & $\begin{array}{l}\text { Farelo de } \\
\text { glúten de } \\
\text { milho } \\
\text { Corn } \\
\text { gluten } \\
\text { meal }\end{array}$ & $\begin{array}{l}\text { Farinha de } \\
\text { carne e } \\
\text { ossos } \\
\text { Meat and } \\
\text { Bone Meal }\end{array}$ & $\begin{array}{c}\text { Farinha de } \\
\text { vísceras de } \\
\text { frango } \\
\text { Poultry by- } \\
\text { product meal }\end{array}$ \\
\hline $\begin{array}{l}\text { Carciofi, et al. } \\
2006\end{array}$ & $86,31 \%$ & $88,13 \%$ & $85,88 \%$ & $84,84 \%$ \\
\hline $\begin{array}{l}\text { Yanka et al. } \\
\text { 2003a }\end{array}$ & - & - & - & 81,0 a $86,6 \%$ \\
\hline $\begin{array}{l}\text { Yanka et al. } \\
\text { 2003b }\end{array}$ & $\begin{array}{l}64,3 \text { a } \\
68,6 \%\end{array}$ & - & - & - \\
\hline $\begin{array}{l}\text { Clapper et al. } \\
2001\end{array}$ & $83,9 \%$ & - & - & $76,9 \%$ \\
\hline $\begin{array}{c}\text { Jonson et al. } \\
1998\end{array}$ & - & - & $\begin{array}{l}79,7 \text { a } \\
85,2 \%\end{array}$ & 80,1 a $82,3 \%$ \\
\hline $\begin{array}{l}\text { Murray et al. } \\
1997\end{array}$ & $88,3 \%$ & - & $88,2 \%$ & $89,5 \%$ \\
\hline Zuo et al. 1996 & $\begin{array}{l}80,3 \text { a } \\
84,6 \%\end{array}$ & - & - & $77,2 \%$ \\
\hline $\begin{array}{c}\text { Case \& } \\
\text { Czarnecki- } \\
\text { Maulden, 1990 }\end{array}$ & - & $74,2 \%$ & - & $65,9 \%$ \\
\hline $\begin{array}{l}\text { Diferença entre } \\
\text { extremos } \\
\text { Difference } \\
\text { among extremes }\end{array}$ & 24,0 & - & 8,5 & 12,3 \\
\hline
\end{tabular}


Apesar de ser o glúten de milho constantemente listado como ingrediente nos rótulos de alimentos para animais de estimação, apenas o trabalho de Case \& Czarnecki-Maulden (1990) fornecem dados de digestibilidade de dieta à base deste ingrediente. Neste estudo, deve-se considerar, no entanto, que os alimentos empregados eram à base de glúten de milho, mas apresentavam significativa quantidade de farinha de carne e ossos e farelo de soja em suas composições, de modo que não é possível uma comparação direta dos resultados encontrados. Alguns autores consideram o glúten de milho uma fonte de proteína relativamente constante em qualidade, mas com digestibilidade não tão alta quanto às fontes de proteína animal (Case et al. 2000). Esta afirmativa não é corroborada por Sa-Fortes (2005) e Carciofi, et al. (2006), que encontraram maiores valores de digestibilidade da proteína para o glúten 60 em relação a fontes animais.

Sa-Fortes (2005) determinou em cães e digestibilidade de sete fontes protéicas para cães, pelo método da substituição (Tabela 6), bem como seus teores de energia metabolizável (Tabela 7).

A soja micronizada e o glúten de milho 60 foram os ingredientes que apresentaram os maiores digestibilidades da PB e MS $(\mathrm{P}<0,05)$. O glúten de milho 60, segundo Butolo (2002), é um subproduto do milho obtido após a remoção da maior parte do amido, gérmen e porções fibrosas. A soja micronizada é produzida a partir de grãos selecionados, submetidos a tratamento térmico, descascamento, pré-moagem e micronização. A menor proporção de fibras e o processamento desses ingredientes podem estar relacionados aos bons valores de digestibilidade verificados neste experimento. Em relação ao farelo de soja, os resultados demonstrados por Sa-Fortes (2005) concordaram com os de Clapper et al. (2001) e Murray et al. (1997) que também não observaram diferenças nas digestibilidades da PB em dietas formuladas com farelo de soja e farinha de vísceras de frango. As menores digestibilidades da MS foram verificadas para a farinha de carne e ossos e a farinha de peixes, o que pode estar relacionado com o maior teor de minerais destes ingredientes.

Tabela 6 - Coeficiente de digestibilidade aparente da matéria seca (CDMS), proteína bruta (CDPB), matéria orgânica (CDMO), extrato etéreo ácido (CDEEA) e amido (CDAMIDO) de ingredientes protéicos para cães (média \pm erro padrão da média). Table 6. Apparent digestibility coefficient of dry matter (CADDM), crude protein (CADCP), acid ether extract (CADAEE) and starch (CADSTARCH) of protein sources for dogs (mean \pm standard error).

\begin{tabular}{|c|c|c|c|c|c|}
\hline Ingredientes Ingredients & $\begin{array}{l}\text { CDMS } \\
\text { CADDM } \\
\end{array}$ & $\begin{array}{l}\text { CDPB } \\
C A D C P \\
\end{array}$ & $\begin{array}{l}\text { CDEEA } \\
\text { CADAEE }\end{array}$ & $\begin{array}{l}\text { CDMO } \\
\text { CADOM }\end{array}$ & $\begin{array}{l}\text { CDAMIDO } \\
\text { CAD Starch }\end{array}$ \\
\hline Glúten de milho 60 Corn gluten meal & $90,5 \pm 2,4^{\mathrm{a}}$ & $92,1 \pm 0,2^{\mathrm{a}}$ & $67,7 \pm 1,5^{\mathrm{d}}$ & $84,6 \pm 1,0^{\mathrm{a}}$ & $96,1 \pm 0,9^{\mathrm{a}}$ \\
\hline $\begin{array}{l}\text { Farelo de soja } \\
\text { Soybean meal }\end{array}$ & $74,3 \pm 1,6^{\mathrm{b}}$ & $83,9 \pm 1,0^{b}$ & $70,1 \pm 0,9^{\mathrm{d}}$ & $74,0 \pm 1,5^{\mathrm{b}}$ & $87,8 \pm 1,3^{\mathrm{b}}$ \\
\hline Soja Micronizada Micronized soybean & $88,0 \pm 1,9^{a}$ & $88,6 \pm 1,5^{\mathrm{a}}$ & $95,0 \pm 0,7^{\mathrm{a}}$ & $87,9 \pm 1,5^{\mathrm{a}}$ & $97,5 \pm 0,6^{\text {a }}$ \\
\hline $\begin{array}{l}\text { Farinha de carne e ossos } \\
\text { Meat and bone meal }\end{array}$ & $59,1 \pm 1,2^{\mathrm{d}}$ & $80,1 \pm 1,6^{\mathrm{b}}$ & $94,3 \pm 0,5^{a}$ & $83,0 \pm 1,8^{\mathrm{a}}$ & -- \\
\hline $\begin{array}{l}\text { Farinha de pena hidrolisada } \\
\text { Hydrolyzed feather meal }\end{array}$ & $64,9 \pm 1,3^{\mathrm{c}}$ & $60,9 \pm 1,5^{c}$ & $79,6 \pm 1,3^{c}$ & $67,2 \pm 1,9^{c}$ & -- \\
\hline $\begin{array}{l}\text { Farinha de peixes } \\
\text { Fish meal }\end{array}$ & $55,9 \pm 1,8^{\mathrm{d}}$ & $80,4 \pm 1,2^{b}$ & $82,0 \pm 2,0^{c}$ & $74,5 \pm 2,3^{b}$ & -- \\
\hline $\begin{array}{l}\text { Farinha de vísceras e frango } \\
\text { Poultry by-product meal }\end{array}$ & $69,0 \pm 2,4^{\mathrm{c}}$ & $81,7 \pm 2,1^{\mathrm{b}}$ & $89,6 \pm 1,2^{\mathrm{b}}$ & $82,5 \pm 2,1^{\mathrm{a}}$ & -- \\
\hline $\begin{array}{l}\text { Fontes de variação } \\
\text { Variation source }\end{array}$ & & & $\begin{array}{l}\text { Probabilidade } \\
\text { Probability }\end{array}$ & & \\
\hline $\begin{array}{l}\text { Animal } \\
\text { Animal }\end{array}$ & 0,8430 & 0,7141 & 0,9676 & 0,8570 & 0,5847 \\
\hline $\begin{array}{l}\text { Período } \\
\text { Period }\end{array}$ & 0,2502 & 0,7317 & 0,1740 & 0,4847 & 0,4587 \\
\hline $\begin{array}{l}\text { Tratamento } \\
\text { Treatment }\end{array}$ & $<0,0001$ & $<0,0001$ & $<0,0001$ & $<0,0001$ & $<0,0001$ \\
\hline $\mathrm{CV} \%$ & 7,0 & 5,1 & 4,1 & 6,2 & 2,5 \\
\hline
\end{tabular}

a,b,c,d - Médias nas colunas seguidas de letras iguais não diferem entre si pelo teste Student Newman Kewls (5\%). Retirado de Sa-Fortes (2005).

a,b,c,d means in the column not sharing a common letter differ by Student Newman Kewls (5\%). Based on Sa-Fortes (2005). 
Os maiores valores de EM foram verificados para soja micronizada e glúten de milho $60(\mathrm{p}<0,05)$. Este maior valor energético pode estar relacionado com os melhores valores de digestibilidade dos nutrientes apresentados pela soja micronizada e o glúten de milho 60 e pela composição química destes ingredientes. Em geral os cães tiveram bom aproveitamento da energia dos ingredientes vegetais. $\mathrm{O}$ processo de extrusão aliado as características nutricionais do glúten de milho 60 , soja micronizada e farelo de soja podem estar relacionados com o bom aproveitamento da energia pelos cães. Os menores valores de EM verificados para a farinha de peixes e farinha de carne e ossos podem ser oriundos da maior concentração de matéria mineral nesses ingredientes.

Tabela 7 - Valores de energia bruta (EB), energia metabolizável (EM) e coeficiente de metabolização da energia bruta (CMEB) de ingredientes protéicos para cães (média \pm erro padrão da média). Table 7 . Gross energy (GE), metabolizable energy (ME) and gross energy metabolization coefficient (GEMC) of protein sources for dogs (mean \pm standard error).

\begin{tabular}{|c|c|c|c|}
\hline $\begin{array}{l}\text { Ingredientes } \\
\text { Ingredients }\end{array}$ & $\begin{array}{l}\text { EB } \\
G E\end{array}$ & $\begin{array}{l}\mathrm{EM} \\
\mathrm{ME}\end{array}$ & $\begin{array}{l}\text { CMEB } \\
\text { GEMC }\end{array}$ \\
\hline $\begin{array}{l}\text { Glúten de milho } 60 \\
\text { Corn gluten meal }\end{array}$ & 5706,2 & $\begin{array}{c}4598,0 \pm \\
75,9^{\mathrm{b}}\end{array}$ & $80,6 \pm 1,3^{\mathrm{ab}}$ \\
\hline $\begin{array}{l}\text { Farelo de soja } \\
\text { Soybean meal }\end{array}$ & 4701,9 & $\begin{array}{c}3421,7 \pm \\
86,2^{\mathrm{c}}\end{array}$ & $72,8 \pm 1,8^{\mathrm{bc}}$ \\
\hline $\begin{array}{l}\text { Soja micronizada } \\
\text { Micronized soybean }\end{array}$ & 5772,1 & $\begin{array}{c}5523,8 \pm \\
75,8^{\mathrm{a}}\end{array}$ & $88,7 \pm 1,4^{\mathrm{a}}$ \\
\hline $\begin{array}{l}\text { Farinha de carne e ossos } \\
\text { Meat and bone meal }\end{array}$ & 3356,7 & $\begin{array}{c}2681,6 \pm \\
74,6^{\mathrm{e}}\end{array}$ & $79,9 \pm 2,2^{\mathrm{ab}}$ \\
\hline $\begin{array}{l}\text { Farinha de penas hidrolisadas } \\
\text { Hydrolyzed feather meal }\end{array}$ & 6335,6 & $\begin{array}{c}3135,7 \pm \\
148,6^{\text {cd }}\end{array}$ & $49,5 \pm 2,4^{\mathrm{d}}$ \\
\hline $\begin{array}{l}\text { Farinha de peixes } \\
\text { Fish meal }\end{array}$ & 3896,3 & $\begin{array}{l}2836,1 \pm \\
211,9^{\mathrm{de}}\end{array}$ & $72,8 \pm 5,4^{\mathrm{bc}}$ \\
\hline $\begin{array}{l}\text { Farinha de vísceras de frango } \\
\text { Poultry by-product meal }\end{array}$ & 5050,0 & $\begin{array}{c}3515,4 \pm \\
133,8^{\mathrm{c}} \\
\end{array}$ & $69,6 \pm 2,6^{c}$ \\
\hline $\begin{array}{l}\text { Fontes de variação } \\
\text { Variation source }\end{array}$ & \multicolumn{3}{|c|}{$\begin{array}{c}\text { Probabilidade } \\
\text { Probability }\end{array}$} \\
\hline $\begin{array}{l}\text { Animal } \\
\text { Animal }\end{array}$ & -- & 0,5371 & 0,5180 \\
\hline $\begin{array}{l}\text { Período } \\
\text { Period }\end{array}$ & -- & 0,5248 & 0,4021 \\
\hline $\begin{array}{l}\text { Tratamento } \\
\text { Treatment }\end{array}$ & -- & $<0,0001$ & $<0,0001$ \\
\hline CV (\%) & -- & 9,3 & 10,2 \\
\hline
\end{tabular}

a,b,c,d - Médias nas colunas seguidas de letras iguais não diferem entre si pelo teste Student Newman Kewls (5\%). Retirado de Sa-Fortes (2005). a,b,c,d means in the column sharing a common letter do not differ by Student Newman Kewls (5\%). Based on Sa-Fortes (2005)
Estudo semelhante, também pelo método da substituição, foi conduzido em gatos por de-Oliveira et al. (2006). Verificaram, também, que o gluten de milho $60 \%$ e a soja micronizada foram bem digeridos pelos gatos, sendo tão bem digeridos ou até melhor aproveitados que a farinha de vísceras de frango e a farinha de carne e ossos (Tabela 8). Desta forma, proteínas vegetais podem ser alternativa interessante também para felinos, apesar das restrições apresentadas por alguns autores (Funaba et al., 2001). Em função de suas boas digestibilidades e composição química, gluten de milho $60 \%$, soja micronizada e farinha de vísceras de frango apresentaram maiores teores de energia metabolizável.

Tabela 8 - Digestibilidade dos nutrientes e energia metabolizável de ingredientes protéicos para gatos. Table 8: Nutrient digestibility and metabolizable energy of protein sources for cats.

\begin{tabular}{|c|c|c|c|c|c|c|}
\hline \multirow{2}{*}{$\begin{array}{c}\text { Digestibilidade } \\
\text { (\%) } \\
\text { Digestibility (\%) }\end{array}$} & \multicolumn{5}{|c|}{$\begin{array}{l}\text { Fonte protéica } \\
\text { Protein source }\end{array}$} & \multirow{2}{*}{ SEM $^{1}$} \\
\hline & $\begin{array}{l}\text { FCO } \\
\text { MBM }\end{array}$ & $\begin{array}{c}\text { FS } \\
\text { SBM }\end{array}$ & $\begin{array}{l}\text { FVF } \\
\text { PBM }\end{array}$ & $\begin{array}{c}\text { FG } \\
\text { CGM } \\
\end{array}$ & $\begin{array}{c}\text { SM } \\
\text { MWS }\end{array}$ & \\
\hline $\begin{array}{l}\text { Matéria seca } \\
\text { Dry matter }\end{array}$ & $48,7^{\mathrm{d}}$ & $64,7^{c}$ & $74,7^{\mathrm{b}}$ & $86,6^{\mathrm{a}}$ & $85,4^{\mathrm{a}}$ & 2,2 \\
\hline $\begin{array}{c}\text { Matéria orgânica } \\
\text { Organic matter } \\
\text { Proteína bruta }\end{array}$ & $84,8^{\mathrm{a}}$ & $67,2^{\mathrm{b}}$ & $92,4^{\mathrm{a}}$ & $88,3^{\mathrm{a}}$ & $88,1^{a}$ & 1,7 \\
\hline $\begin{array}{c}\text { Crude protein } \\
\text { Extrato etéreo } \\
\text { ácido }\end{array}$ & $81,1^{\mathrm{b}}$ & $80,3^{\mathrm{b}}$ & $91,4^{\mathrm{a}}$ & $95,6^{\mathrm{a}}$ & $87,4^{\mathrm{ab}}$ & 1,2 \\
\hline $\begin{array}{c}\text { Acid hydrolyzed } \\
\text { fat } \\
\text { Energi bruta }\end{array}$ & $70,9^{\mathrm{ab}}$ & $75,1^{\mathrm{ab}}$ & $82,4^{\mathrm{a}}$ & $67,4^{\mathrm{b}}$ & $74,0^{\mathrm{ab}}$ & 1,4 \\
\hline Crude energy & $86,1^{a}$ & $68,4^{b}$ & $91,6^{\mathrm{a}}$ & $88,3^{a}$ & $87,5^{a}$ & 1,6 \\
\hline $\begin{array}{c}\text { Energia } \\
\text { metabolizável } \\
(\mathrm{kcal} / \mathrm{kg}) \\
\text { Metabolizable } \\
\text { energy }(\mathrm{kcal} / \mathrm{kg})\end{array}$ & $2262,3^{d}$ & $\underset{\mathrm{cd}}{2822,6}$ & $\begin{array}{c}3537 \\
4^{\mathrm{bc}}\end{array}$ & $\underset{\mathrm{a}}{4525,8}$ & $\underset{\mathrm{ab}}{4061,9}$ & 150,0 \\
\hline
\end{tabular}

FCO - farinha de carne e osso; FS - farelo de soja; FVF - farinha de vísceras de frango; FG - farelo de glúten de milho 60\%; SM soja micronizada. MBM - meat and bone meal; SBM - soybean meal ;PBM - poultry by-product meal; CGM - corn gluten meal; MWS - micronized whole soybean.

1 EPM - erro padrão da média ( $\mathrm{n}=6$ por dieta). SEM - pooled standard error of the mean $(n=6$ per diet).

$a, b, c, d$ - Médias na mesma linha sem uma letra em comum são diferentes pelo teste de Tukey $(p<0,05)$. Retirado de de-Oliveira, et al. (2006). ${ }^{a, b, c, d}$ Within a row, means without a common superscript differ for cats $(P<0.05)$ by Turkey's Test (de-Oliveira, et al., 2006). 


\section{Literatura consultada}

ANFALPET - ASSOCIAÇÃO NACIONAL DOS FABRICANTES DE ALIMENTOS PARA ANIMAIS DE ESTIMAÇÃO. Institucional. Disponível em:

$<$ http://www.anfalpet.org.br/asp/anfal_interna.asp?ir=anfal_institucion al.asp\&cod_inst=4529> Acesso em: 15 de novembro de 2007.

ANNISON, G. Relationship between the levels of soluble nonstarch polysaccharides and the apparent metabolizable energy of wheats assayed in broiler chickens. Journal of Agricultural and Food Chemistry, v.39, p.1252-1256, 1991.

ANNISON, G.; TOPPING, D.L. Nutritional role of resistant starch: chemical structure vs. physiological function. Annual Review of Nutrition, v. 14, p. 297-320, 1994.

APPLETON, D.J.; RAND, J. S.; PRIEST, J. et al. Dietary carbohydrate source affects glucose concentrations, insulin secretion, and food intake in overweight cats. Nutrition Research., v. 24, p. 447-467, 2004.

BAZOLLI, R. S. ; VASCONCELLOS, R. S. ; BRUNETTO, M. A. et al. Influence of particles size of corn, sorghum, and rice in extrused dog foods on diet digestibility and postprandial glucose response. In: 11th Congress of the European Society of Veterinary and Comparative Nutrition, 2007, Leipzig. Proceedings of the 11th ESVCN Congress. Leipzig : Merkur Druck, 2007. p. 55-55.

BAZOLLI, R. S. Influência do grau de moagem de ingredientes amiláceos utilizados em rações extrusadas sobre os aspectos digestivos e respostas metabólicas em cães. Jaboticabal: Faculdade de Ciências Agrárias e Veterinárias, 2007. 72p. Tese (Doutorado em Medicina Veterinária) Faculdade de Ciências Agrárias e Veterinárias, Universidade Estadual Paulista, 2007.

BEHALL, K. M. et al. Effect of starch structure on glucose and insulin responses in adults. American Journal of Clinical Nutrition, v. 47, p. 428-432, 1988.

BEHALL, K. M.; SCHOLFIELD, D. J.; YUHANIAK, I. et al. Diets containing high amylose vs. amylopectin starch: Effect on metabolic variables in human subjects. American Journal of Clinical Nutrition., v. 49, p. 337-344,1989.

BELAY, T.; SHIELDS-, R. O. Jr; WIERNUSZ, C. J.; et al. Evaluation of nutrient digestibility and stool quality of rice (Oryza sativa) based canine diets. Veterinary Clinical Nutrition, v. 4, n. 4, p. 122-129, 1997.

BELLAVER, C. Ingredientes de origem animal destinados à fabricação de rações. In: SIMPÓSIO SOBRE INGREDIENTES NA ALIMENTAÇÃO ANIMAL, 1., 2001, Campinas. Anais... Campinas, SP:CBNA, 2001. p.167-190.

BOMTEMPO, V. Nutrition and health of dogs and cats: evolution of petfood. Veterinary Research Communications, v. 29, n.2, p.45-50, 2005. Suppl.

BOUCHARD, G. F.; SUNVOLD, G. D. Improving canine glycemic response to a meal with dietary starch. In: The North American Veterinary Conference, 1999, Orlando. Proceedings: recent advances in clinical management of diabetes mellitus, Orlando: The Iams company press, 1999. p. 16-19.

BRAND MILLER, J.C. Importance of glycemic index in diabetes. American Journal of Clinical Nutrition, v. 59S, p. 747-752, 1994.

BURROWS, C.F.; KRONFELD, D. S.; BANTA, C. A. et al. Effects of fiber on digestibility and transit time in dogs. Journal of Nutrition, v. 112, n. 9, p. 1726-1732, 1982.

BUTOLO, J.E. Qualidade de ingredientes na alimentação animal. Campinas: Colégio Brasileiro de Alimentação Animal, 2002. 430p.

CARCIOFI, A. C. ; TAKAKURA, F. S. ; de-OLIVEIRA, L. D. et al. Effects of six carbohydrate sources on dog diet digestibility and postprandial glucose and insulin response. Journal of Animal Physiology and Animal Nutrition, 2008 (no prelo)

CARCIOFI, A.C., PONTIERI, R., FERREIRA, C.F. et al. Avaliação de dietas com diferentes fontes protéicas para cães adultos. Revista Brazileira de Zootecnia, v. 35, p. 754-760, 2006.

CASE,L.P.; CAREY,D.P.; HIRAKAWA,D.A. et al. Canine and feline nutrition. A resource for companion animal professionals. 2ed. St. Loius: Mosby, 2000. 592p.

CASE,L.P.; CZARNECKI-MAULDEN,G.L., Protein requirements of growing pups fed practical dry-type diets containing mixed-protein sources. American Journal of Veterinary Research, v.51, n.5, p.808812, 1990

CHEEKE, P.R. Applied animal nutrition: feeds and feeding. 2. ed. New Jersey: Prentice-Hall, 1999. p. 26-81.

CHOCT, M.; ANNISON, G. Anti-nutritive activity of wheat arabinoxylans: role of viscosity and gut microflora. British Poultry Science, v.33, p.821-834, 1992

CLAPPER,G.M.; GRIESHOP,C.M..; MERCHEN,N.R.; et al. Ileal and total tract nutrient digestibilities and fecal characteristics of dogs as affect by soybean protein inclusion in dry, extruded diets. Journal Animal Science, v.79, p. 1523-1532, 2001

COWELL, C.S.; STOUT, N.P.; BRINKMANN, M.F. et al. Making commercial pet foods. In: HAND, M.S.; THATCHER, C.D.; REMILLARD, R.L.; ROUDEBUSH, P. (ed). Small Animal Clinical Nutrition, 4th ed. Kansas: Mark Morris Institute, 2000. p.127-146.

De-OLIVEIRA, L D.; TAKAKURA, F. S.; VASCONCELLOS, R. S. et al. Digestibility of starch sources for dogs and cats In: Congress of the European Society of Veterinary and Comparative Nutrition, 10, 2006, Nantes. Congress of the European Society of Veterinary and Comparative Nutrition, 10., 2006. v.2006. p.101 - 101

De-OLIVEIRA, L. D.. Avaliação de fontes de amido para alimentos extrusados para gatos. 2005. 106 p. Dissertação (Mestrado em Medicina Veterinária). Faculdade de Ciências Agrárias e Veterinárias, Universidade Estadual Paulista, Jaboticabal, 2005.

ENGLYST, H. N. et al. Analyses and measurement of nutritionally important starch fractions. American Journal of Clinical Nutrition, v. 46, n.2, p.s33-s50, 1992

ENGLYST, H. N.; CUMMINGS, J. H. Non-starch polysaccharides (dietary fiber) and resistant starch. Advances in Experimental Medicine and Biology, v. 270, p. 205-223, 1990.

ENGLYST, H.N.; HUDSON, G.J. The classification and measurement of dietary carbohydrates. Food Chemistry, v. 57, n. 1, p. 15-21, 1996.

ENGLYST, K.N.; VINOY, S.; ENGLYST, H. N. et al. Glycaemic index of cereal products explained by their content of rapidly and slowly available glucose. British Journal of Nutrition, v. 89, n. 3, p. 329-340, 2003.

FADEL, J.; NEWMAN, C. W.; NEWMAN, R. K. et al. Effects of extrusion cooking of barley on ileal and fecal digestibilities of dietary components in pigs. Canadian Journal of Animal Science, v. 68, p. 891897, 1988.

FAHEY Jr., G. C.; MERCHEN, N. R.; CORBIN, J. E. et al. Dietary fiber for dogs: 1- Effects of graded levels of dietary beet pulp on nutrient intake, digestibility, metabolizable energy and digesta mean retention time. Journal of Animal Science, v. 68, n. 12, p. 4221-4228, 1990a.

FAHEY Jr., G. C.; MERCHEN, N. R.; CORBIN, J. E. et al. Dietary fiber for dogs: 2- Iso-total dietary fiber (TDF) addidions of divergent fiber sources to dogs diets and their effects on nutrient intake, digestibility, metabolizable energy and digesta mean retention time. Journal of Animal Science, v. 68, n. 12, p. 4229-4235, 1990b.

FAO. 1998. Carbohydrates in human nutrition: a Joint FAO/WHO Report. Rome, 1998 FAO (Food and Nutrition Paper 66).

FUNABA, M.; TANAK, T.; KANEKO, M. et al. Fish meal vs. corn gluten meal as a protein source for dry cat food. Journal of Veterinary Medical Science. v. 63, n. 12, p. 1355-1357, 2001.

HENDRIKS, W.H.; EMMENS, M.M.; TRASS, B. et al. Heat processing changes the protein quality of canned cat foods as measured with a rat bioassay. Journal of Animal Science, v. 77, p. 669-676, 1999.

HOLSTE, L. C.; NELSON, R. W.; FELDMAN E. C. et al. Effect of dry, soft moist, and canned dog foods on postprandial blood glucose and insulin concentrations in healthy dogs. American Journal of Veterinary Research, v. 50, p. 984-989, 1989.

HOSENEY, R.C. Minor constituints of cereals. In: Principles of cereal science and tecnology. 2nd ed. Sant Poul: American Association of Cereal Chemisty. 1994.

JENKINS, D. J.; WOLEVER, T. M.; TAYLOR, R. H. et al. Glycemic index of foods: A physiological basis for carbohydrate exchange. American Journal of Clinical Nutrition, v. 34, p. 362-366, 1981.

JOHNS, D.C.; LOW, C.K.; JAMES, K.A.C. Comparison of amino acid digestibility using ileal digesta from growing chickens and canulated adult cockerels. British Poultry Science, v.27, p.679-685.1986. 
JOHNSON, M.L.; PARSON, C..M.; FEHEY Jr., G. C. et al. Effects of species raw material source, ash content, and processing temperature on amino acid digestibility of animal by-product meals by cecectomized roosters and ilealy cannulated dogs. Journal of Animal Science, v. 76, n.4, p.1112-1122, 1998.

KAMALU, B. P. Digestibility of a nutritionally-balanced cassava (Manihot esculenta Crantz) diet and its effect on growth in young male dogs. British Journal of Nutrition, v. 2, n. 66, p. 199-208, 1991.

KRONFELD, D. S. Nature and use of commercial dog foods. Journal of the American Veterinary Medical. Assoc., v. 166, p. 487-493, 1975.

LOBO, A.R.; SILVA, G.M.L. Amido resistente e suas propriedades físicoquímicas. Revista de Nutrição., v.16, n.2, p. 219-226, 2003.

LOWE, J. A. Effective use of new and novel concepts in pet food design. In: Proc. Alltech's Fifth Annual Symposium. Biotechnology in the Feed Industry. Alltech's Technical Publications, Nicholasville, KY. P209221, 1989.

MEYER, H. New findings in canine nutrition. Kraftfutter, n.3, p. 113-117, 1997.

MURRAY, S. M.; FAHEY Jr, G. C.; MERCHEN, N. R. et al. Evaluation of selected high-starch flours as ingredients in canine diets. Journal of Animal Science, Savoy, v. 77, n. 8, p. 2180-2186, 1999.

MURRAY, S.M.; FLICKINGER, E.A.; PATIL, A.R. et al. In vitro fermentation characteristics of native and processed cereal grains and potato starch using ileal chime from dogs. Journal of Animal Science, Savoy, v. 79, p. 435-444, 2001.

MURRAY,S.M.; PATIL,A.R.; FAHEY Jr., G. C. et al. Raw and rendered animal by-products as ingredients in dog diets. Journal of Animal Science, v.79, n .9, p. 2497-2505, 1997.

NELSON, R. W.; HIMSEL, C. A.; FELDMAN E. C. et al. Glucose tolerance and insulin response in normal weight and obese cats. American Journal of Veterinary Research, v. 51, p.1357-1362, 1990.

NGUYEN, P.; DUMON, H.; MARTIN, P.B.L. et al. Composition of meal influences changes in postprandial incremental glucose and insulin in healthy dogs. Journal of Nutrition, v. 124, p. 2707S-2711S, 1994.

NISHIMUNE, T.; YAKUSHIJI, T.; SUMIMOTO, T. et al. Glycemic response and fiber content of some foods. American Journal of Clinical Nutrition, v. 54, p. 414-419, 1991.

NRC - Nutrient Requirements of Dogs and Cats. National Research Council. The National Academy Press: Washington, D.C. 2006. 398p.

NUTTALL, F.Q. MOORADINA, A.D.; GANNON, M.C. et al. Effect of protein ingestion on the glucose and insulin response to a standardized oral glucose load. Diabetes Care, v. 7, n. 5, p. 465-470, 1984.

OWSLEY, W.F. KNABE, D.A.; TANKSLEY Jr, T.D. Effect of sorghum particle size on digestibility of nutrients at the terminal ileum and over the total digestive tract of growing-finishing pigs. Journal of Animal Science, v. 52, n. 3, p. 557-566, 1981

PARSONS, C.M.; CASTANON, F.; HAN, Y. Protein and amino acid quality of meat and bone meal. Poultry Science, v.61, p.2241-2246, 1997.

POND, W.G; CHURCH, D.C., POND, K.R. Basic Animal Nutrition and feeding. $4^{a}$ ed. John Wiley, New York, 1995. 615p.
ROONEY, L.W.; PFLUGFELDER, R.L. Factors affecting starch digestibility with special emphasis on sorghum and corn. Journal of Animal Science, v. 63, p. 1607-1623, 1986.

ROSTAGNO, H.S.; ALBINO, L. F. T.; DONZELE, J. L. et al. Tabelas brasileiras para aves e suínos (composição de alimentos e exigências nutricionais). Viçosa, MG: UFV, 2005.186p.

SA FORTES, C. M.L. Composição química, digestibilidade e energia metabolizável de ingredientes amiláceos e protéicos para cães. 2005. 88 p. Tese (Doutorado). Faculdade de Ciências Agrárias e Veterinárias, Universidade Estadual Paulista, Jaboticabal, 2006.

SILVA Jr, J. W. et al. Digestibilidade de dietas com diferentes fontes de carboidratos e sua influência na glicêmica e insulinemia de cães. Ciência Agrotécnica. v.29, n.2, p.436-443, 2005.

STEIFF, E.L.; BAUER, J.E. Nutritional adequacy of diets formulated for companion animals. Journal of the American Veterinary Medical Association Schaumburg, v. 219, n.5, p. 601-604, 2001.

SUNVOLD, G. D. Dietary fiber for dogs and cats: An historical perspective. In: IAMS INTERNATIONAL NUTRITION SYMPOSIUM, 1996, Wilmington. Proceeding of the recent advances in canine and feline nutrition research, Wilmington: Orange Frazer press, 1996. p. 3-14.

SUNVOLD, G. D. FAHEY Jr. G. C.; MERCHEN N. R. et al. Dietary fiber for cats: in vitro fermentation of selected fiber sources by cat fecal inoculum and in vivo utilization of diets containing selected fiber sources and their blends. Journal of Animal Science, v. 73, p. 23292339, 1995.

TWOMEY, L.N. PLUSKE, J. R.; ROWE J.B. et al. The replacement value of sorghum and maize with or without supplemental enzymes for rice in extruded dog food. Animal Feed Science and Technology, v. 18, p. 61-69, 2003.

TWOMEY, L.N.; PEHICK, D.W.; ROWE, J.B. et al. The use of sorghum and corn as alternatives to rice in dog foods. Journal of Nutrition, v.132, p. 1704S-1705S, 2002.

VAN SOEST, P. J. Nutritional ecology of the ruminant: ruminant metabolism, nutritional strategies, the celullolytic fermentation and the chemistry of forages and plant fiber. Ithaca: Cornell University Press, 1994.

WALKER, J.A.; HARMON, D.L.; GROSS, K.L. et al. Evaluation of nutrient utilization in the canine using the ileal cannulation technique. Journal of Nutrition, v.124, p.2672S-2676S, 1994.

WANG, X.; PARSONS, C.M. Effect of raw material source, processing systems and processing temperatures on amino acid digestibility of meat and bone meals. Poultry Science, v.77, p.834-841. 1998.

WOLTER, R.; DO SOCORRO, E.P.; HOUDRE, C. Faceal and ileal digestibility in the dog diets rich in wheat or tapioca starch. Recueil de Medicine Veterinaire, v. 174, n.5-6, p. 45-55, 1998.

YANKA,R.M.; JAMIKORN,U.; TRUE,A.D.; et al Evaluation of soybean meal as a protein source in canine foods. Animal Feed Science and Thecnology. v.109, p.121-132, 2003b.

ZUO,Y.; FEHEY Jr,G.C; MERCHEN,N.R. et al. Digestion responses to low oligosaccharide soybean meal by illealy-cannulated dogs. Journal Animal Science, v.7, p.2441-2449, 1996. 